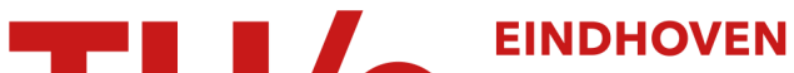 \\ UNIVERSITY OF \\ TECHNOLOGY
}

\section{Recruitment of knee joint ligaments}

Citation for published version (APA):

Blankevoort, L., Huiskes, H. W. J., \& Lange, de, A. (1991). Recruitment of knee joint ligaments. Journal of Biomechanical Engineering : Transactions of the ASME, 113(1), 94-103. https://doi.org/10.1115/1.2894090

DOI:

$10.1115 / 1.2894090$

Document status and date:

Published: 01/01/1991

\section{Document Version:}

Publisher's PDF, also known as Version of Record (includes final page, issue and volume numbers)

\section{Please check the document version of this publication:}

- A submitted manuscript is the version of the article upon submission and before peer-review. There can be important differences between the submitted version and the official published version of record. People interested in the research are advised to contact the author for the final version of the publication, or visit the $\mathrm{DOI}$ to the publisher's website.

- The final author version and the galley proof are versions of the publication after peer review.

- The final published version features the final layout of the paper including the volume, issue and page numbers.

Link to publication

\section{General rights}

Copyright and moral rights for the publications made accessible in the public portal are retained by the authors and/or other copyright owners and it is a condition of accessing publications that users recognise and abide by the legal requirements associated with these rights.

- Users may download and print one copy of any publication from the public portal for the purpose of private study or research.

- You may not further distribute the material or use it for any profit-making activity or commercial gain

- You may freely distribute the URL identifying the publication in the public portal.

If the publication is distributed under the terms of Article $25 \mathrm{fa}$ of the Dutch Copyright Act, indicated by the "Taverne" license above, please follow below link for the End User Agreement:

www.tue.nl/taverne

\section{Take down policy}

If you believe that this document breaches copyright please contact us at:

openaccess@tue.nl

providing details and we will investigate your claim. 


\section{Recruitment of Knee Joint Ligaments}

On the basis of earlier reported data on the in vitro kinematics of passive knee-joint motions of four knee specimens, the length changes of ligament fiber bundles were determined by using the points of insertion on the tibia and femur. The kinematic data and the insertions of the ligaments were obtained by using Roentgenstereophotogrammetry. Different fiber bundles of the anterior and posterior cruciate ligaments and the medial and lateral collateral ligaments were identified. On the basis of an assumption for the maximal strain of each ligament fiber bundle during the experiments, the minimal recruitment length and the probability of recruitment were defined and determined. The motions covered the range from extension to 95 degrees flexion and the loading conditions included internal or external moments of $3 \mathrm{Nm}$ and anterior or posterior forces of $30 \mathrm{~N}$. The ligament length and recruitment patterns were found to be consistent for some ligament bundles and less consistent for other ligament bundles. The most posterior bundle of each ligament was recruited in extension and the lower flexion angles, whereas the anterior bundle was recruited for the higher flexion angles. External rotation generally recruited the collateral ligaments, while internal rotation recruited the cruciate ligaments. However, the anterior bundle of the posterior cruciate ligament was recruited with external rotation at the higher flexion angles. At the lower flexion angles, the anterior cruciate and the lateral collateral ligaments were recruited with an anterior force. The recruitment of the posterior cruciate ligament with a posterior force showed that neither its most anterior nor its most posterior bundle was recruited at the lower flexion angles. Hence, the posterior restraint must have been provided by the intermediate fiber bundles, which were not considered in the experiment. At the higher flexion angles, the anterior bundles of the anterior cruciate ligament and the posterior cruciate ligament were found to be recruited with anterior and posterior forces, respectively. The minimal recruitment length and the recruitment probability of ligament fiber bundles are useful parameters for the evaluation of ligament length changes in those experiments where no other method can be used to determine the zero strain lengths, ligament strains and tensions.

\section{Introduction}

The passive motion characteristics of the human knee-joint depend on the mechanical and structural interrelation between the articular surfaces, the ligaments and the menisci. Because of the relative incongruency of the articular surfaces, the ligaments play an important role in providing for the passive stability of the joint. For the development of adequate diagnostic and surgical procedures, it is essential to understand the role of individual ligament fiber bundles as motion restraints.

A wide range of experimental tools has been used to investigate ligament function. One approach is to measure increases of joint laxity after sequential cutting of the ligaments (e.g., Markolf et al., 1976; Gollehon et al., 1987). Another approach is to measure the reduction of restraining forces or moments after sequential cutting (Butler et al., 1980; Piziali et al., 1980;

${ }^{1}$ Presently at the TNO Leather and Shoe Research Institute, Waalwijk, The Netherlands.

Contributed by the Bioengineering Division for publication in the JoURNal of Biomechanical Enoineering. Manuscript received by the Bioengineering Division October 30, 1989; revised manuscript received October 20, 1990.
Seering et al., 1980). The latter approach is more suitable for direct quantification of the contribution of a ligament to the motion restraint. Ligament forces have been measured with buckle-transducers attached to ligaments or ligament bundles (Lewis et al., 1982; Ahmed et al., 1987) or estimated by measuring the strains in the bone adjacent to the ligament insertion (France et al., 1983). Several techniques have been used to measure ligament length changes or strains: Roentgenstereophotogrammetry (van Dijk et al., 1979; van Dijk, 1983), six degrees-of-freedom spatial linkages (Hefzy and Grood, 1986), an electromagnetic six degrees-of-freedom digitizer (Sidles et al., 1988), Liquid Metal Strain gauges (Meglan et al., 1985), Hall Effect Strain Transducers (Arms et al., 1983) and omega transducers instrumented with strain gauges (Claes and Schmid, 1985). The Hall Effect Strain Transducers have been applied for in vivo experiments of ACL strain measurements during an arthroscopic procedure (Beynnon et al., 1989; Fleming et al., 1989). Henning et al. (1985) proposed a dual technique of measuring in vivo the displacement of a point on the anter- 
Table 1 Characteristics of the Tested Knee Joint Specimens

\begin{tabular}{cccc}
\hline Specimen & Left/Right & Age & Sex \\
\hline 1 & $\mathrm{R}$ & 43 & $\mathrm{M}$ \\
2 & $\mathrm{~L}$ & 53 & $\mathrm{~F}$ \\
$3^{*}$ & $\mathrm{R}$ & 74 & $\mathrm{~F}$ \\
$4^{*}$ & $\mathrm{~L}$ & 74 & $\mathrm{~F}$ \\
\hline
\end{tabular}

*Bilateral

omedial bundle of the ACL located $1 \mathrm{~cm}$ from the tibial insertion, simultaneously with the deformation of the subchondral bone at the tibial ACL attachment.

The major problem in the analysis of length patterns or strain changes is that the measured parameters cannot directly be related to "real" ligament strains or to ligament tensions, if the zero strain or the zero load length of ligament fiber bundles is not determined. Beynnon et al. (1989) and Fleming et al. (1989) determined the zero strain by palpation of the ligament near the transducer and observing the transducer output at the point where the ligament bundle became taut. This is a relatively uncertain procedure because of the very low stiffness of ligamentous tissue at low loads and strains. Arms et al. (1986) cut the ligament loose after the motion experiment and determined the strain for the unloaded situation. The strain readings which were obtained during the motion experiments were corrected with the zero strain value. Due to the visco-elastic behavior of ligamentous tissue, the strain relaxation of a ligament may continue for several hours. Hence, the real zero strain will have an unknown systematic error.

In the present study, an alternative method was introduced to analyze ligament length changes. This method is particularly suited for those experiments where the zero strain is not determined. The minimal recruitment length of a ligament fiber bundle was defined as the minimal straight distance between the insertions which a ligament bundle required to be tensed. A ligament fiber bundle was assumed to be recruited when it was lengthened above its minimal recruitment length. Beyond this length, the bundle could actually have been tensed and could thus have participated in balancing the external loads on the joint. Conversely, it was assumed not to be recruited for lengths below the minimal recruitment length and was thus considered to have been slack. The minimal recruitment length was determined from a series of experimentally obtained ligament bundle lengths, on the basis of an assumption for the maximal strain of a ligament fiber bundle. The ligament length changes and recruitment patterns of ligament fiber bundles of the cruciate ligaments and the collateral ligaments is reported for passive motion patterns of four knee specimens. The ligament recruitment patterns were derived from the ligament length patterns, which were measured with Roentgenstereophotogrammetry (Selvik, 1974, 1989) in an in vitro experiment of passive knee joint motions (Blankevoort et al., 1988) in which the insertions of ligament fiber bundles were measured in addition to the kinematic parameters. The use of minimal recruitment length and ligament recruitment can be considered as a concise and illustrative method to analyze and describe the behavior of knee joint ligaments for passive joint motions, lacking the complexity and some of the uncertainties associated with the interpretation of ligament length or strain values.

\section{Methods}

Experimental Procedure. The ligament length patterns were determined from previously reported motion data of in vitro experiments on four human knees. The knees were numbered 1 to 4 and their characteristics are listed in Table 1 . Two knees ( 3 and 4 ) were from the same donor.

The knees were freshly frozen and thawed prior to the experiments. Roentgenographic and manual examinations did not show any abnormalities which could have led to exclusion

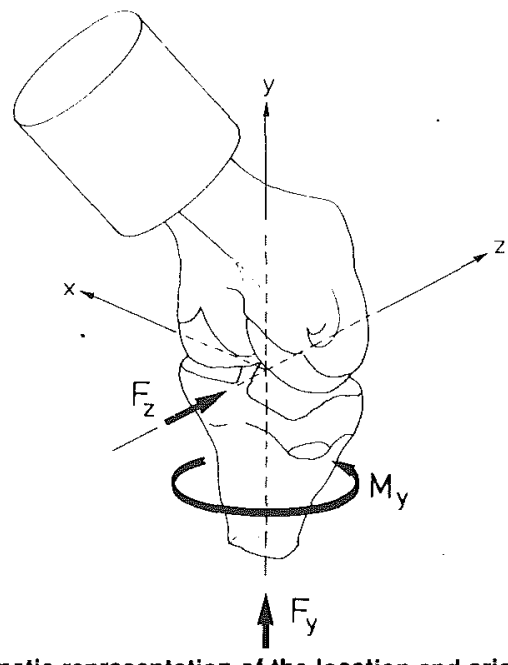

Fig. 1 Schematic representation of the location and orientation of the body fixed axes of the tibia and the load configurations which were used in this study. The origin of the tibial coordinate axes is located at the tibial insertion of the posterior bundle of the anterior cruciate ligament (pAC). The $x$-axis points medially; rotation around this axis represents flexion. The $y$-axis is aligned with the tibial shaft and points proximally: rotation around this axis represents internal (positive) and external (negative) rotation. The $z$-axis points anteriorly; rotation around this axis represents varus (positive) and valgus (negative) rotation. $F_{y}$ indicates an axial compressive force, $M_{y}$ indicates an internal (positive) or an external moment (negative) and $F_{z}$ indicates an anterior force (positive) or a posterior force (negative).

from the experiment. The knee was cut $15 \mathrm{~cm}$ above and below the joint line. All soft tissues, including the skin were left intact. The fibula was fixed to the tibia using a Kirchner wire. Tantalum pellets of $0.8 \mathrm{~mm}$ diameter were used as radiopaque markers for the Roentgenstereophotogrammetric measurements. Six of these pellets were fixed into the cortex of each bone using a two-component glue.

The tibia and femur were mounted in a motion and loading apparatus of which a complete description is given by Blankevoort et al. (1988). The motion and loading apparatus allowed the joint six degrees-of-freedom of motion. The distal-proximal translation and flexion were realized through a mechanism on the femoral side, and axial rotation, varus-valgus rotation, anterior-posterior translation and medial-lateral translation were realized on the tibial side. The flexion angle could be prescribed in intervals of 5 degrees minimally. Except for some small friction in the ball-bearings of the apparatus, there were no constraints with respect to the remaining five degrees-offreedom of motion. Through the apparatus, external loads could be applied to the joint. These were internal and external moments $\left(M_{y}\right)$ of 3 and $6 \mathrm{Nm}$ about the long axis of the tibia, anterior and posterior forces $\left(F_{z}\right)$ of 30 and $45 \mathrm{~N}$, and axial forces $\left(F_{y}\right)$ along the tibial shaft of 150 and $300 \mathrm{~N}$, and combinations thereof (Fig. 1) (Blankevoort et al., 1988). The anterior-posterior forces were directed along the anteriorposterior axis of the tibia as defined for the joint in extension and were independent of the coupled axial rotation of the tibia relative to the femur.

First, the load was applied and then the joint was moved through flexion in sequential flexion steps from extension to approximately 95 degrees flexion. For the unloaded case and the cases with an internal or external moment in combination with axial forces, there were seven flexion positions. With anterior-posterior loads, five flexion positions were used. At each flexion angle, the relative positions of the bones were measured by using Roentgenstereogrammetry (RSP, Selvik, 1974, 1989). The two Roentgen tubes were located in a transverse plane relative to the joint either at the medial or lateral side. The Roentgen films were located on the other side of the joint in a plane parallel to the sagittal plane. The joint specimen and the two roentgen tubes thus formed, by approximation, 
Table 2 Abbreviations

\begin{tabular}{|c|c|}
\hline $\mathrm{ACL}-\mathrm{An}$ & aAC - anterior bundle \\
\hline CL - Posterior Cruciate Ligament: & $\begin{array}{l}\mathrm{pAC} \\
\mathrm{aPC} \\
\mathrm{pPC}\end{array}$ \\
\hline LCL - Lateral Collateral Ligament: & $\begin{array}{l}\text { aLC - anterior bundle } \\
\text { sLC - superior bundle } \\
\text { pLC - posterior bundle }\end{array}$ \\
\hline MCL - Mec & $\begin{array}{l}\text { aMC - anterior bundle } \\
\text { iMC - inferior bundle } \\
\text { pMC - posterior bundle }\end{array}$ \\
\hline $\begin{array}{c}\text { CMCL - deep (Capsular) fibers of } \\
\text { Medial Collateral Ligamen } \\
\end{array}$ & $\begin{array}{l}\text { aCM - anterior bundle } \\
\text { pCM - posterior bundle }\end{array}$ \\
\hline
\end{tabular}

an equally sided triangle with angles of 60 degrees (Blankevoort et al., 1988). The two-dimensional positions of the projections of the markers on the Roentgen films were evaluated on a twodimensional digitizer. ${ }^{2}$ The marker images were measured with an accuracy of $20 \mu \mathrm{m}$. A computer program reconstructed the spatial coordinates of the markers with a spatial accuracy of less than $50 \mu \mathrm{m}$ (Blankevoort et al., 1988). The three-dimensional marker coordinates were used to calculate the kinematic parameters to describe the motion from the reference position of the joint to each position during the stepwise flexion motions (Selvik, 1974, 1989).

After the experiments, the joint was dissected and the ligaments were exposed. The peripheral fiber bundles of the four knee ligaments were chosen because they were expected to show the largest length changes. Of the anterior (ACL) and posterior (PCL) cruciate ligaments, the two fiber bundles which were macroscopically identified represented the anterior and posterior margins of each ligament. The guideline for the bundle identification was the more-or-less elliptic shape of the femoral insertion of the ACL and PCL; the apexes of the long axis of the elliptical shape identified the extremes of the insertion areas. The approximately $2 \mathrm{~mm}^{2}$ sized insertion areas (app. $1.5 \mathrm{~mm}$ diameter) inside these apexes were marked by placing a pellet of $1 \mathrm{~mm}$ diameter. For the anterior bundle of the ACL $(\mathrm{aAC})$, the most anterior and superior insertion area on the femur was identified. The bundle originating from this area was followed to its anterior tibial insertion, which was then marked. The same procedure was followed for the posterior bundle of the ACL (pAC), which originated from the most posterior and inferior part of the femoral insertion and was followed to its posterior tibial insertion. The anterior bundle of the PCL (aPC) was identified by the most anterior insertion area on the femur and was followed to the lateral part of the tibial PCL insertion. The posterior bundle of the PCL (pPC) was identified through its most posterior insertion on the femur and followed to the medial tibial insertion area.

For the lateral collateral ligament, the most anterior, posterior, and superior insertion areas were identified and the respective fiber bundles originating from those areas were followed to the insertions on the fibula. For the medial collateral ligament, three femoral insertion areas were identified: posterior, anterior, and inferior. For the anterior and posterior insertion areas, ligament fibers could be macroscopically followed either as the deep, more-or-less capsular part of the MCL running to the medial bony edge of the tibia just below the medial meniscus, or as the superficial MCL running to the more distal insertions at the tibial shaft. For the inferior femoral insertion, a fiber bundle was followed only to the tibial insertion at the shaft. Hence, for the MCL there were three peripheral fibers identified for the superficial part of the MCL and two for the deep fiber bundles of the MCL.

The markers were placed within $2 \mathrm{~mm}^{2}$ sized insertion areas which were identified according to the procedures described above. The identification procedure was repeated by two ob-

${ }^{2}$ Aristomat $104-M^{\oplus}$. servers until agreement was obtained on the precise locations. It was estimated that the markers could be placed within 0.5 $\mathrm{mm}$ off the center of the identified insertion area. After the identification of the insertions and the placement of the insertion markers, an additional Roentgen double exposure was made and evaluated in order to reconstruct the 3-D coordinates of the ligament insertion markers relative to the femoral and tibial coordinate systems. See Table 2 for an overview of the ligament fiber bundles which were identified in this study.

Joint Motion and Ligament Length. Joint motion was described by using two Cartesian coordinate systems $E_{f}$ and $E_{t}$ which were introduced in the femur and tibia, respectively, by a calibration procedure in the RSP system (Blankevoort et al., 1988). $E_{f}$ was considered to be space-fixed. A point $P$ on the tibia is expressed by the vector $\mathbf{p}$ relative to $E_{t}$. $P$ is expressed with respect to the femoral coordinate system $E_{f}$ as

$$
\mathbf{P}=\mathbf{D}+R \mathbf{p},
$$

where $\mathbf{D}$ denotes the position of the origin of $E_{\text {, with respect }}$ to $E_{f}$ and $R$ denotes the rotation matrix. The rotation matrix $R$ depends on three independent variables, referred to as Euler angles (Selvik, 1974, 1989), which are subsequent rotations about the three axes of the reference system $E_{t}$. The adopted rotation sequence was: first rotation about the x-axis, representing flexion, second rotation about the y-axis, representing internal-external rotation and third rotation about the $z$-axis representing varus-valgus rotation (Fig. 1) (Blankevoort et al., 1988). The reference systems $E_{f}$ and $E_{t}$ were defined such that they coincided for the joint in extension.

Ligament length changes were calculated from the joint motions by assuming that the ligament bundles run in straight lines between the insertions. The length $L_{j}$ of a line element $j$, representing a ligament bundle, was calculated from the insertion points $\mathbf{X}_{f j}$ on the femur and $\mathbf{x}_{t j}$ on the tibia by:

$$
L_{j}=\left|\mathbf{X}_{f j}-\mathbf{D}-R \mathbf{x}_{i j}\right|
$$

Minimal Recruitment Length. The minimal recruitment length $R_{j}$ of a ligament fiber bundle $j$ was determined by its maximal length $L_{\max , j}$, as measured in the experiments, and the assumed maximum strain $e_{m}$. In a particular joint position, the length $L_{j}$ of a ligament bundle $j$, the associated strain $e_{j}$, and the zero-strain length $L_{0 j}$ are related by:

$$
\begin{gathered}
e_{j}=\left(L_{j}-L_{0 j}\right) / L_{0 j} \\
L_{0 j}=L_{j} /\left(1+e_{j}\right)
\end{gathered}
$$

For all loading cases and all flexion positions, the ligament length $L_{j}$ was determined by the insertion points of the ligament bundle and the kinematic parameters. For one of these flexion positions the ligament length $L_{j}$ was maximal. This maximal length $L_{\max , j}$ was associated with a maximal strain $e_{\max , j}$. The central assumption was that the maximal strain values were equal for all ligament bundles; hence $e_{\max , j}=e_{m}$. With this maximal strain value, the ligament length for the associated zero strain was then defined as the minimal recruitment length $R_{j}$ :

$$
R_{j}=L_{\max , j} /\left(1+e_{m}\right)
$$

Based on the experimental determination of $L_{\max , j}$, and a particular value for $e_{m}, R_{j}$ could be determined for each ligament fiber bundle. In a joint position where $L_{j}>R_{j}$, the bundle was assumed to be recruited. It should be noted that the minimal recruitment length $R_{j}$ was not equal to the zero-strain length, since the real value of the maximal strain in each ligament fiber bundle remained unknown.

For the evaluation of the experiments, two levels for the maximal strains were used, $e_{m}=e_{5}=0.05$ (or 5 percent strain) and $e_{m}=e_{10}=0.10$ (or 10 percent strain). The 10 percent strain level was chosen a little lower than the failure strain of ligamentous tissue which was reported by Butler et al. (1986) to 
be in the range of 11 to 19 percent. The 5 percent strain level was chosen because of the moderate loading conditions in the experiments (Blankevoort et al., 1988). The associated minimal recruitment lengths are denoted by $R_{5}$ and $R_{10}$, respectively.

Recruitment Probability. The minimal recruitment length was a measure based on an assumed maximal strain $e_{m}$ which was a priori unknown. For increasing ligament lengths above the minimal recruitment level, there was an increasing probability that the particular ligament bundle was really recruited during the experiments. The recruitment probability $P_{j}$ for a ligament bundle $j$ was defined by

$$
\begin{array}{ll}
P_{j}=\left(L_{j}-R_{j}\right) /\left(e_{m} R_{j}\right) & \text { for } L_{j}>R_{j}, \\
P_{j}=0 & \text { for } L_{j} \leq R_{j} .
\end{array}
$$

With this definition, the recruitment probability $P_{j}$ will be zero for ligament lengths smaller than the minimal recruitment length and will have the value 1 for the length associated with the assumed maximal strain $e_{m}$.

Accuracy. For one knee specimen (spec. 3), two experimental flexion series were measured twice. One flexion motion was performed with an axial force of $150 \mathrm{~N}$ in combination with an internal moment of $3 \mathrm{Nm}$, and the other with an

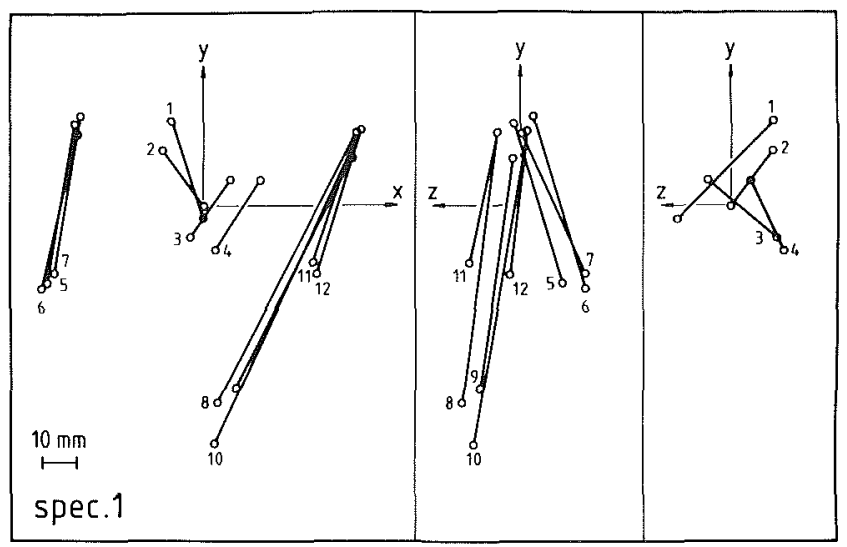

Fig. 2(a)

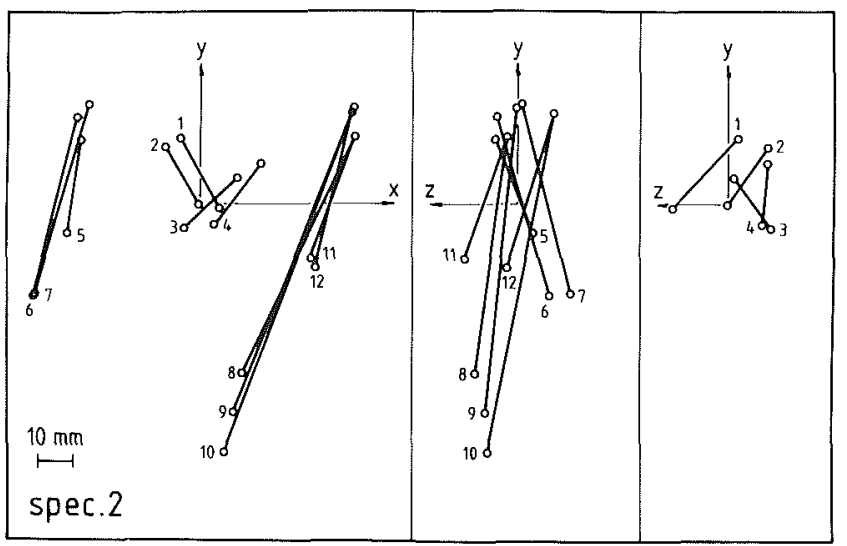

Fig. 2(b) anterior force of $30 \mathrm{~N}$. This repetition of two experimental series, with a total of 11 flexion positions, showed that the length of a line element could be determined with a standard deviation of $0.3 \mathrm{~mm}$. This implies an accuracy of the relative length change of 0.015 for the shortest ligaments $(20 \mathrm{~mm})$ and 0.003 for the longest ligaments $(100 \mathrm{~mm})$. The accuracy of the Euler rotations and the translations was found to be better than 0.4 degrees and $0.2 \mathrm{~mm}$, respectively (Blankevoort et al., 1988).

\section{Results}

Ligament Insertions and Minimal Recruitment Lengths. The insertion locations of the identified ligament bundles and the twelve line elements representing these bundles of the four specimens are shown in Figs. $2(a-d)$. The anatomical differences between the joint specimens which were observed during the identification of the ligament bundles are reflected in this representation for the joint in extension. Note, for instance, the femoral insertion of the anterior cruciate ligament (ACL) in specimen 1 as compared to the other specimens ( $y z$-view), and femoral insertion of the posterior cruciate ligament (PCL) in specimen 4 ( $x y$-view). Surprisingly, the two bilateral specimens 3 and 4 differed remarkably with respect to the orientation of the lateral collateral ligament (LCL) $(y z$ view).

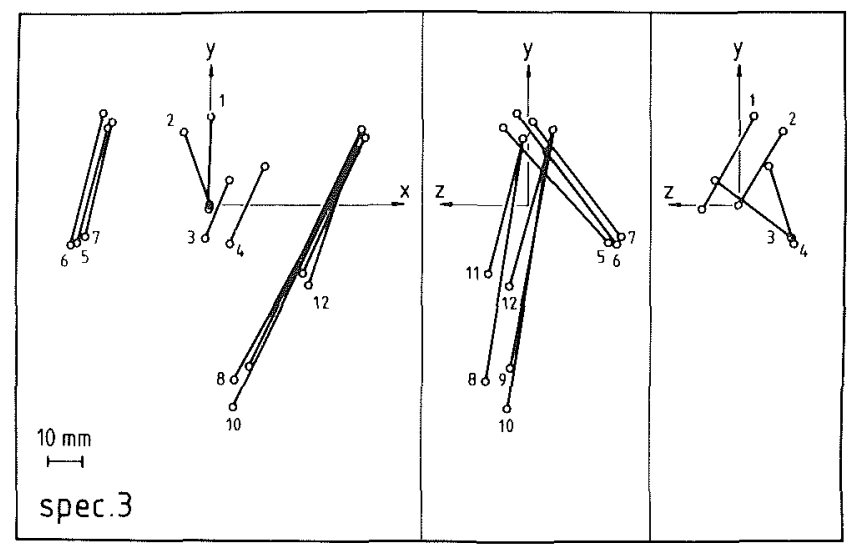

Fig. 2(c)

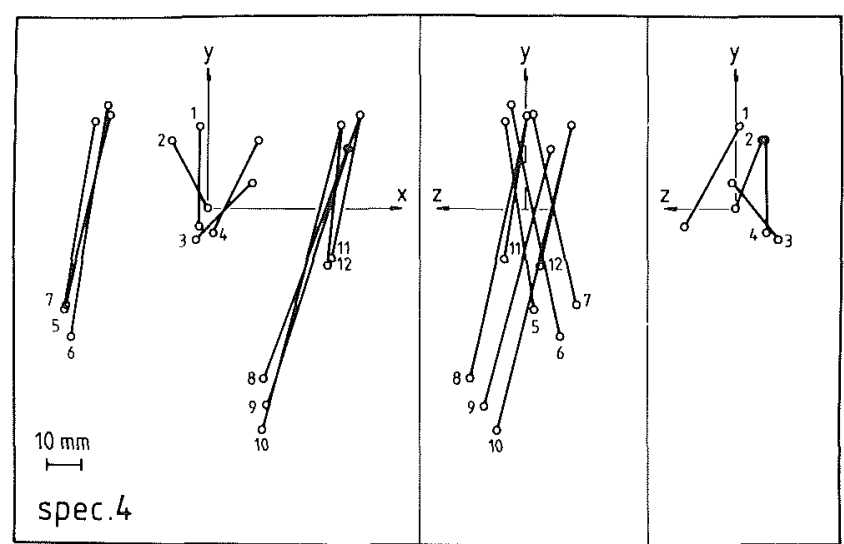

Fig. 2(d)

Fig. 2(a-d) The locations of the ligament insertions and the line elements representing individual fiber bundles of the ligaments of the four specimens from this study. The insertions and line elements are shown

\begin{tabular}{|c|c|c|c|}
\hline $\begin{array}{l}1=a A C \\
2=p A C \\
3=a P C \\
4=p P C\end{array}$ & $\begin{array}{l}5=\mathrm{aLC} \\
6=\mathrm{sLC} \\
7=\mathrm{pLC}\end{array}$ & $\begin{aligned} 8 & =a M C \\
9 & =i M C \\
10 & =p M C\end{aligned}$ & $\begin{array}{l}11=\mathrm{aCM} \\
12=\mathrm{pCM}\end{array}$ \\
\hline
\end{tabular}
relative to the tibial coordinate system and for the joint in extension.

(Refer to Table 2 for the meaning of the abbreviations) 
Table 3 Ligament lengths $L$ at the reference position (extension, unloaded) of the ligament fiber bundles of the four knee specimens and the minimal recruitment lengths $R_{5}$ and $R_{10}[\mathrm{~mm}]$ of the line elements with a maximal strain level $e_{m}$ of 5 and 10 percent, respectively. In case the initial length $L$ is higher than $R_{5}$, the figures for $L$ are given in bold type.

\begin{tabular}{|c|c|c|c|c|c|c|c|c|c|c|c|c|}
\hline specimen & & 1 & & & 2 & & & 3 & & & 4 & \\
\hline $\begin{array}{l}\text { line } \\
\text { elem. }\end{array}$ & $\begin{array}{c}\mathrm{L} \\
{[\mathrm{mm}]}\end{array}$ & $\begin{array}{c}\mathrm{R}_{S} \\
{[\mathrm{~mm}]}\end{array}$ & $\begin{array}{c}\mathbf{R}_{\mathbf{1 0}} \\
{[\mathrm{mm}]}\end{array}$ & $\begin{array}{c}\mathrm{L} \\
{[\mathrm{mm}]}\end{array}$ & $\begin{array}{c}\mathrm{R}_{\mathrm{s}} \\
{[\mathrm{mm}]}\end{array}$ & $\begin{array}{c}\mathbf{R}_{10} \\
{[\mathrm{~mm}]}\end{array}$ & $\begin{array}{c}\mathrm{L} \\
{[\mathrm{mm}]}\end{array}$ & $\begin{array}{c}\mathbf{R}_{5} \\
{[\mathrm{~mm}]}\end{array}$ & $\begin{array}{c}\mathrm{R}_{10} \\
{[\mathrm{~mm}]}\end{array}$ & $\stackrel{\mathrm{L}}{[\mathrm{mm}]}$ & $\begin{array}{c}\mathrm{R}_{5} \\
{[\mathrm{~mm}]}\end{array}$ & $\begin{array}{c}\mathbf{R}_{10} \\
{[\mathrm{~mm}]}\end{array}$ \\
\hline $\begin{array}{l}\mathrm{aAC} \\
\mathrm{pAC}\end{array}$ & $\begin{array}{l}40.3 \\
23.3\end{array}$ & $\begin{array}{l}40.8 \\
23.2\end{array}$ & $\begin{array}{l}38.9 \\
22.2\end{array}$ & $\begin{array}{l}29.5 \\
22.1\end{array}$ & $\begin{array}{l}33.6 \\
21.6\end{array}$ & $\begin{array}{l}32.1 \\
20.6\end{array}$ & $\begin{array}{l}30.2 \\
25.4\end{array}$ & $\begin{array}{l}31.9 \\
24.6\end{array}$ & $\begin{array}{l}30.5 \\
23.4\end{array}$ & $\begin{array}{l}32.2 \\
23.2\end{array}$ & $\begin{array}{l}34.2 \\
24.0\end{array}$ & $\begin{array}{l}32.6 \\
22.9\end{array}$ \\
\hline $\mathrm{aPC}^{\circ}$ & & $\begin{array}{l}35.5 \\
31.7\end{array}$ & $\begin{array}{l}33.9 \\
30.3\end{array}$ & $\begin{array}{l}23.2 \\
21.8\end{array}$ & $\begin{array}{l}31.5 \\
21.9\end{array}$ & $\begin{array}{l}30.0 \\
20.9\end{array}$ & $\begin{array}{l}28.1 \\
24.8\end{array}$ & $\begin{array}{l}37.4 \\
25.1\end{array}$ & $\begin{array}{l}35.6 \\
23.9\end{array}$ & $\begin{array}{l}26.2 \\
29.2\end{array}$ & $\begin{array}{l}32.3 \\
28.9\end{array}$ & $\begin{array}{l}30.8 \\
27.6\end{array}$ \\
\hline aLC & $\begin{array}{l}47.7 \\
43.7 \\
\mathbf{5 2 . 3}\end{array}$ & $\begin{array}{l}50.2 \\
47.9 \\
51.8\end{array}$ & $\begin{array}{l}47.9 \\
45.7 \\
49.4\end{array}$ & $\begin{array}{l}29.0 \\
54.1 \\
57.6\end{array}$ & $\begin{array}{l}37.4 \\
56.6 \\
56.1\end{array}$ & $\begin{array}{l}35.6 \\
54.0 \\
53.6\end{array}$ & $\begin{array}{l}44.9 \\
47.6 \\
41.8\end{array}$ & $\begin{array}{l}47.8 \\
48.2 \\
41.9\end{array}$ & $\begin{array}{l}45.6 \\
46.0 \\
40.0\end{array}$ & $\begin{array}{l}55.0 \\
68.4 \\
56.9\end{array}$ & $\begin{array}{l}53.1 \\
66.0 \\
55.2\end{array}$ & $\begin{array}{l}50.7 \\
63.0 \\
52.7\end{array}$ \\
\hline $\begin{array}{l}\text { aMC } \\
\text { iMC } \\
\text { pMC }\end{array}$ & $\begin{array}{l}86.8 \\
73.6 \\
99.3\end{array}$ & $\begin{array}{l}84.9 \\
71.1 \\
95.6\end{array}$ & $\begin{array}{l}81.1 \\
67.9 \\
91.2\end{array}$ & $\begin{array}{r}74.5 \\
93.2 \\
\mathbf{1 0 4 . 6}\end{array}$ & $\begin{array}{r}75.6 \\
89.2 \\
100.1\end{array}$ & $\begin{array}{l}72.2 \\
85.2 \\
95.6\end{array}$ & $\begin{array}{l}78.8 \\
69.2 \\
87.6\end{array}$ & $\begin{array}{l}77.1 \\
66.9 \\
84.4\end{array}$ & $\begin{array}{l}73.6 \\
63.8 \\
80.5\end{array}$ & $\begin{array}{l}81.0 \\
78.9 \\
91.5\end{array}$ & $\begin{array}{l}79.4 \\
76.1 \\
88.0\end{array}$ & $\begin{array}{l}75.7 \\
72.6 \\
84.0\end{array}$ \\
\hline $\begin{array}{l}\mathrm{aCM} \\
\mathrm{pCM}\end{array}$ & $\begin{array}{l}39.7 \\
\mathbf{4 3 . 1}\end{array}$ & $\begin{array}{l}46.0 \\
42.5\end{array}$ & $\begin{array}{l}43.9 \\
40.6\end{array}$ & $\begin{array}{l}38.7 \\
47.4\end{array}$ & $\begin{array}{l}48.1 \\
47.4\end{array}$ & $\begin{array}{l}45.9 \\
45.3\end{array}$ & $\begin{array}{l}43.5 \\
48.3\end{array}$ & $\begin{array}{l}45.6 \\
47.8\end{array}$ & $\begin{array}{l}43.6 \\
45.6\end{array}$ & $\begin{array}{l}42.2 \\
\mathbf{4 0 . 9}\end{array}$ & $\begin{array}{l}44.0 \\
40.3\end{array}$ & $\begin{array}{l}42.0 \\
38.5\end{array}$ \\
\hline
\end{tabular}

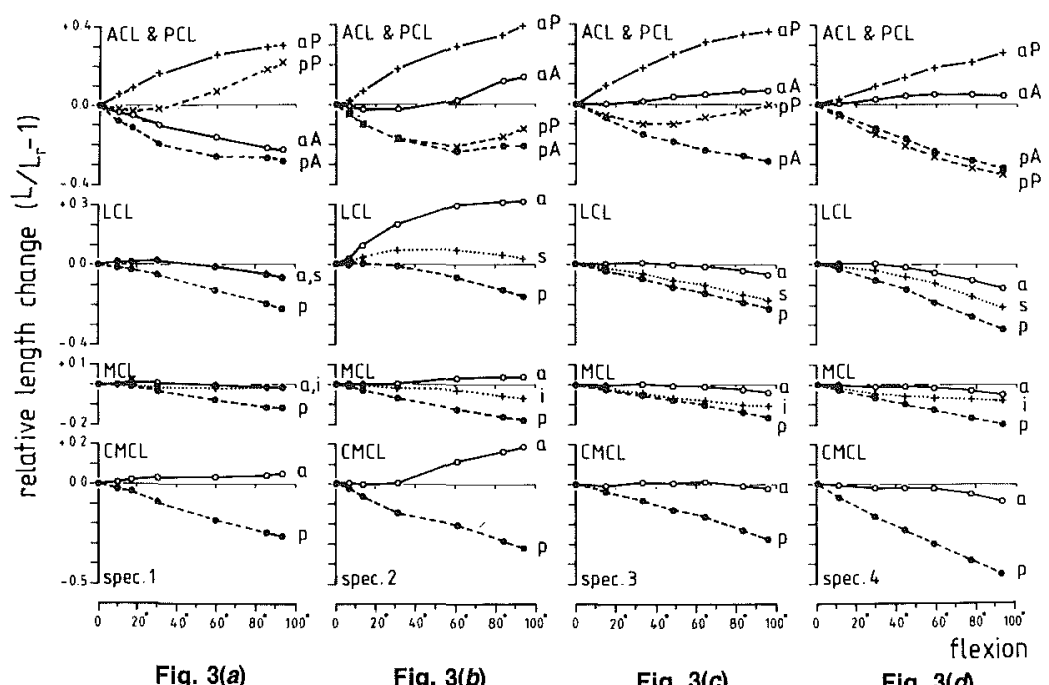

$\begin{array}{llll}\text { Fig. 3(a) } & \text { Fig. 3(b) } & \text { Fig. 3(c) } & \text { Fig. 3(d) }\end{array}$

Fig. $3(a-d)$ The relative length changes as functions of flexion of the Iwelve ligament line elements of each knee for a neutral motion pathway, i.e., flexion without external forces

The reference ligament bundle lengths for the joints in extension and the minimal recruitment lengths $R_{5}$ and $R_{10}$, for maximal strains $e_{m}$ of 5 percent and 10 percent, are listed in Table 3. In the cases where the reference length is lower than the minimal recruitment length, the line element was slack in the neutral extension position. This was the case for PCL and the anterior bundle of the ACL (aAC) with the 5 percent criterion for $e_{m}$. The posterior bundle of the LCL (pLC) was assumed to be recruited. In nearly all cases, the line elements of the medial collateral ligament (MCL) were above the minimal recruitment level, whereas only the posterior bundle of the deep fibers of the MCL (pCM) was recruited. From equation (4) it can be derived that $R_{5}$ is larger than $R_{10}$, by a factor of approximately 0.05 . Hence, by the using $R_{10}$ criterion, more fiber bundles will be assumed recruited, as was the case for the posterior bundle of the PCL (pPC) and the superior bundle of the LCL (sLC) for the joint in extension.

Length Changes and Ligament Recruitment. The minimal recruitment lengths of the ligament bundles were determined from the lengths of all flexion motions and loading configurations, but only five flexion series with a specific loading configuration were chosen from the study of Blankevoort et al. (1988) to be reported. The reason for this was that the effects of the additional axial forces on the motions and lig- ament length changes were small relative to the values for flexion with only the internal or external moments of $3 \mathrm{Nm}$. Also the increase of the axial moment from 3 to $6 \mathrm{Nm}$ and the increase of the anterior-posterior forces from 30 to $45 \mathrm{~N}$ did not much change the motion patterns. The five selected flexion motions were thus considered as being representative of the general passive motion characteristics (Blankevoort et al., 1988). The first was a flexion series with no external loads, the second and third were with an internal and external moment of $3 \mathrm{Nm}$, respectively, and the fourth and fifth were with an anterior and posterior force of $30 \mathrm{~N}$, respectively.

The length changes of the twelve line elements, relative to the lengths in extension, are shown in Figs. $3(a-d)$ as functions of flexion, for a neutral motion pathway of the four specimens. A neutral motion pathway in this study was a motion from extension to 95 degrees flexion with no external loads, giving no or only small tibial rotations (Blankevoort et al., 1988). The neutral flexion motion was not a highly reproducible motion, as was reflected by the small variations of the axial rotations for repetitive trials (Blankevoort et al., 1988). However, the small variations did not have much effect on the resulting ligament length patterns as was evidenced by standard deviations of the relative length changes of between 0.005 and 0.02 depending on the reference length of the line element. The relative length changes, as compared between the four speci- 


\section{assumed recruitment}

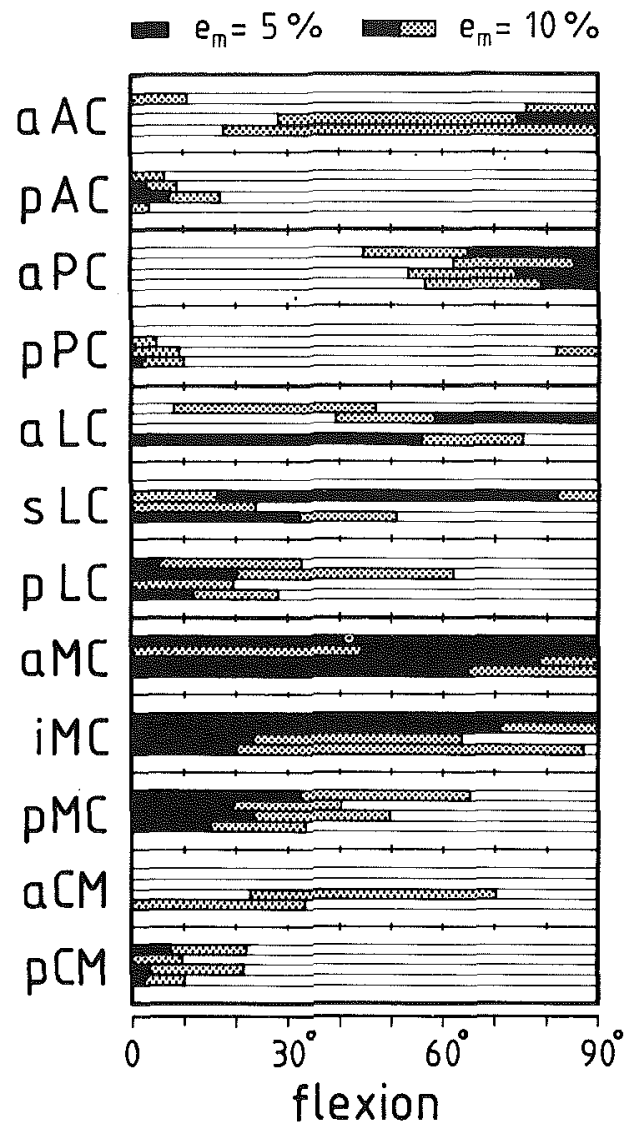

Fig. 4 Assumed recruitment of the ligament fiber bundles as functions of flexion. For each ligament fiber bundle, the four horizontal bars rep. resent the four individual joint specimens (from top to boltom specimens 1 to 4). With either black or grey is indicaled at which flexion angles recruitment is assumed for any of the two assumed maximal strain levels:

White: no recruitment

Black: recruitment with assumed maximal strain $e_{m}=0.05$ (5 percent)

Black and grey: recruitment with assumed maximal strain $e_{m}=0.10$ (10 percent)

(If a ligament fiber bundle is recruited for $e_{m}=0.05$, then it also recruited for $e_{m}=0.10$.)

mens, were similar for six of the twelve ligament bundles (aPC, $\mathrm{pAC}, \mathrm{pLC}, \mathrm{aMC}, \mathrm{pMC}$ and $\mathrm{pCM}$ ). In at least three of the four specimens, similarity was found in all but two ligament fiber bundles. No consistency was found with respect to the relative length changes of the posterior bundle of the PCL (pPC) and the superior bundle of the LCL (sLC). In each ligament, the relative length of the anterior bundle became higher than that of the posterior bundle as flexion progressed.

The ligament recruitment patterns during flexion are indicated in Fig. 4, where the assumed recruitment of each ligament fiber bundle is indicated for each of the four specimens for both the 5 and 10 percent maximal strain levels. It should be noted that if a ligament fiber is assumed recruited for the 5 percent maximum strain level, it is also assumed recruited for the 10 percent maximum strain level. Sometimes recruitment of a ligament bundle for a particular flexion angle was only found in one or two specimens and sometimes recruitment was found in all four specimens for the low recruitment level $R_{5}$. Recruitment of the cruciate ligaments depended on the location of the ligament bundle, in the sense that the anterior bundles (aAC, aPC) were recruited for the higher flexion angles and the posterior bundles ( $\mathrm{pPC}, \mathrm{pAC}$ ) near extension. The anterior

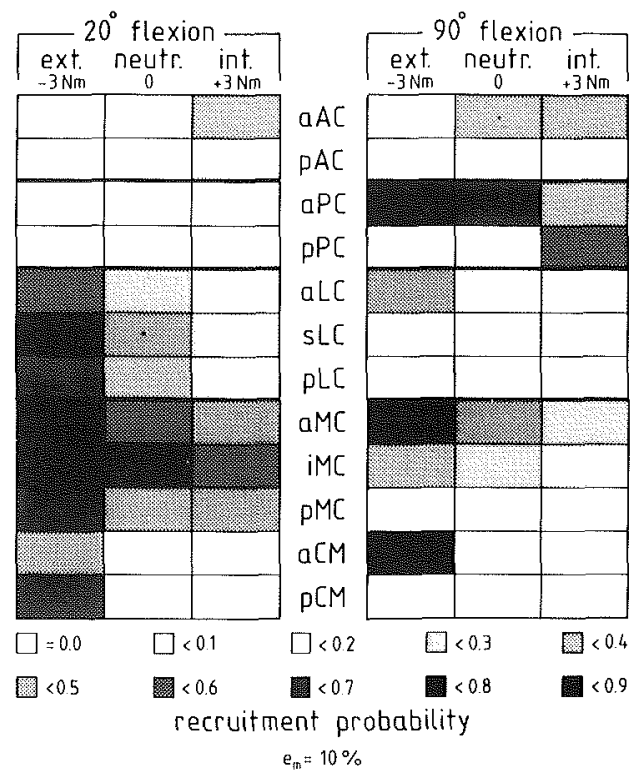

Fig. 5 Recruitment probability ( $e_{m}=10$ percent) of the ligament fiber bundles at 20 and 90 degrees flexion averaged over the four knee spec. imens, for external $(-3 \mathrm{Nm})$, neutral $(0 \mathrm{Nm})$ and internal $(+3 \mathrm{Nm})$ rotation.
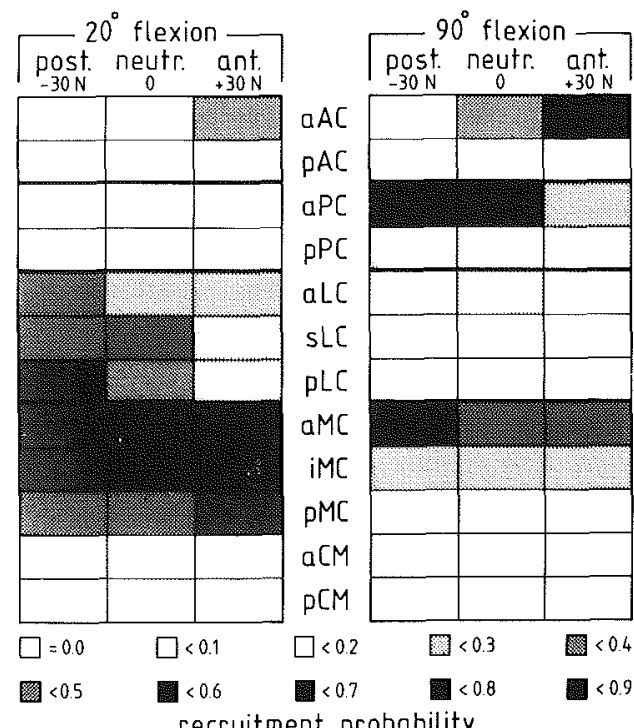

$$
\mathrm{e}_{\mathrm{m}}=10 \%
$$

Fig. 6 Recruitment probability $\left(e_{m}=10\right.$ percent) of the ligament fiber bundles at 20 and 90 degrees flexion averaged over the four knee spec. imens, for the posterior $(-30 \mathrm{~N})$ force, for the unloaded case (neutral) and for the anterior $(+30 \mathrm{~N})$ force.

and posterior bundles of the PCL were not recruited over a large flexion range between 10 and 50 degrees of flexion with the 10 percent maximal strain criterion. If the maximal strain level of 5 percent is adopted, the two ACL bundles were also slack over a large flexion range.

The recruitment of the LCL was variable among the four joint specimens, but its posterior bundle ( $\mathrm{pLC}$ ) was not recruited beyond a certain flexion angle with either of the maximal strain levels. The anterior bundle of the MCL (aMC) was recruited over the entire flexion range, whereas the posterior bundle (pMC) was slack for flexion angles over 60 degrees. Of the deep fibers of the MCL (CMCL), only the posterior bundle (pCM) was recruited between extension and 20 degrees flexion.

Ligament Recruitment for Tibial Moments and AnteriorPosterior Forces. The recruitment results for tibial moments 
(Fig. 5) and for anterior-posterior forces (Fig. 6) are given for two flexion angles, 20 and 90 degrees, to represent the recruitment characteristics for the lower and higher flexion angles, respectively. With $e_{m}=10$ percent as the maximal strain criterion, the average recruitment probabilities of the four specimens are shown.

With internal or external moments of $3 \mathrm{Nm}$ applied on the tibia, the tibia will internally or externally rotate until the limit of rotation is reached. This moment level is low relative to physiological loading conditions, and was merely chosen to define the passive tibial rotation limits (Blankevoort et al., 1988). Except for the anterior bundle of the PCL (aPC), the recruitment probability of the cruciate ligaments increased with internal rotation at 20 and 90 degrees flexion (Fig. 5). At 90 degrees flexion, the anterior bundle of the PCL (aPC) showed increasing recruitment probability with external rotation. The average recruitment probability of the collateral ligaments decreased with internal rotation and increased with external rotation. The posterior bundle of the ACL (pAC) and the posterior bundles of the collateral ligaments ( $\mathrm{pLC}, \mathrm{pMC}, \mathrm{pCM})$ were slack at 90 degrees flexion for all rotation positions.

The application of only anterior-posterior forces of $\pm 30 \mathrm{~N}$ on the tibia not only resulted in anterior-posterior translations of the tibia relative to the femur, but also in an internal rotation with an anterior force and an external rotation with a posterior force (Blankevoort et al., 1988). This reflected in the resulting recruitment probability with anterior-posterior forces (Fig. 6). Particularly for the cruciate ligaments and the lateral collateral ligament, the anterior force tended to recruit those ligaments which were recruited for internal rotation and a posterior force recruited those ligaments which were recruited for external rotation. With anterior-posterior forces alone, the collateral ligaments did not reach those values for the recruitment probability which were found with external rotation. Surprisingly, the two fiber bundles of the PCL (aPC and $\mathrm{pPC}$ ) were not recruited with a posterior force at 20 degrees of flexion, where those of LCL (aLC, sLC and pLC) did show increasing recruitment probability. The ACL was recruited with an anterior force, where also an increasing recruitment probability was found for two bundles of the MCL (iMC and pMC). At 90 degrees flexion, the anterior bundle of the ACL (aAC) was recruited to restrain the anterior force, in absence of assistance by the collateral ligaments. The posterior cruciate was recruited at 90 degrees flexion with a posterior force, whereby the highest recruitment probability was found for its anterior bundle (aPC). The recruitment changes of the medial collateral ligament were small with anterior-posterior loading.

\section{Discussion}

Because the ligament length was calculated from the straight distance between the two insertions of a ligament fiber bundle, the relative length changes did not directly reflect the ligament strain changes. A ligament might have been bent in its course over the bony surfaces, which was certainly the case for the MCL wrapping around the bony edge of the medial tibial plateau, and it might also have occurred for the ACL when it interacts with the intercondylar notch for the joint in extension. More important however, the ligament fiber lengths reported in this study and in previous studies (Grood et al., 1983; Hefzy and Grood 1986; Hefzy et al., 1986; Walker et al., 1988), as well as strains measured with transducers directly attached to the ligaments (Meglan et al., 1985; Arms et al., 1983; Claes and Schmid, 1985), did not directly represent "real" ligament strains, since the initial strain at the reference position or the zero load length of the ligament fiber bundles were not known.

In this paper, the minimal recruitment length was introduced as a parameter to estimate at which joint positions the ligament can be assumed recruited, on the basis of an assumption for the maximal strain in a ligament bundle which might have occurred during the experiments. The real maximal strain which had occurred may not have been equal to the assumed maximal strain. The assumed maximal strain was merely introduced to indicate some maximum level for ligamentous tissue at moderate loading conditions. A strain level based on experimentally determined failure strains for ligamentous tissue may also be used as the assumed maximal strain. For ligament lengths below the minimal recruitment length, the ligament involved can be considered slack and not recruited. If a ligament bundle was not slack for lengths below the minimal recruitment length, then the strain for the observed maximal length will of course have exceeded the adopted maximum strain level, which would have led to ligament failure if the assumed maximal strain was equal to the failure strain. Therefore, the ligament bundle will certainly be slack if shorter than the minimal recruitment length given the adopted maximal strain level. On the other hand, for length values above the minimal recruitment length it is not certain whether a ligament fiber bundle is taut, because the real maximal strain which has occurred during the experiments might have been much lower than the assumed maximal strain. Because of this uncertainty, the recruitment probability was introduced. The higher its value, the higher the chance that a ligament fiber bundle was not slack but actually recruited.

Due to this aspect of the recruitment probability, the average recruitment probability of multiple specimens incorporated the intra-specimens differences. The value zero (white $=0.0$ in Figs. 5 and 6) means that no recruitment was found in any of the specimens, whereas values between 0.1 and 0.8 (grey) have a dual meaning in the sense that either one or two specimens had a high recruitment probability and the others had low values or the recruitment probability was moderate in all specimens. High values for the average recruitment probability means that in all specimens a high recruitment probability was found. A large shift in the average recruitment probability from low to high values means that there were increasing ligament lengths in the joint specimens.

The idea of using ligament length data to determine at which joint positions the ligaments were slack or taut on the basis of the maximal ligament strain originated from Grood et al. (1983), but they considered only one motion pathway. They did not expand on this idea in later analyses (Hefzy and Grood, 1986; Hefzy et al., 1986). Arms and Butler (1989) used the term recruitment in a study which was directed at determining the recruitment of the individual fiber bundles of the cruciate ligaments. In order to determine the zero lengths of 15 fiber bundles representing the ACL and 13 bundles representing the PCL, they used a mathematical model of the anterior-posterior motion of the knee at different flexion angles. They combined a failure criterion of 15 percent strain at maximal anteriorposterior displacement with the lengths of the bundles at different flexion positions. No account was made of other motions and the contributions of other joint structures. The predicted anterior-posterior laxity curves were in the range of those reported in the literature. No data was reported on the values of the minimal recruitment lengths of the one specimen which was used for the anatomical data.

Maximal failure strains of the human ligaments were reported to range between 11 and 30 percent (Butler et al., 1986; Noyes and Grood, 1976; Trent et al., 1976; Kennedy et al., 1976). Assuming the physiological loading range of ligaments and tendons to be about one third of their ultimate strength (Crisp, 1972; Viidik, 1980) and regarding their non-linear stressstrain relationship, values between 5 and 10 percent are reasonable choices for the assumed maximal strains during physiological loading conditions, of which the 10 percent level is close to the lowest reported failure strains. Because in the present study the loading conditions were relatively low, the maximal ligament strain probably had not reached values higher than 10 percent. 
Anatomical differences between the specimens of the insertions and the reference lengths of the ligament fiber bundles were evident. These variations were much larger than the estimated error in the identification of the insertion locations and may, at least partly, have accounted for the quantitative differences of the ligament lengths patterns. Hefzy and Grood (1986) and Hefzy et al. (1986) showed in their studies on the length patterns of the anterior and posterior cruciate ligaments that, in particular, variation of the femoral insertion location yielded large changes of the length patterns. This was supported by the observations of Sidles et al. (1988) who mapped the potential femoral insertions for the maximal absolute strains for different ranges of motion. In the results of these studies, qualitative as well as quantitative matches can be found with each of the specimens in this study, depending on the choice of tibial and femoral insertions. For this reason it was not surprising that with respect to cruciate ligament behavior, the comparison with other reported length patterns or "strain" changes, qualitative agreement was found as frequently as no agreement at all.

The variations of the relative length patterns between the four specimens is reflected in the variations of the assumed recruitment, although for some bundles quantitative agreement was found. Because of the very low slope for the curve representing the relative length change as functions of flexion, small changes of the minimal recruitment length may have resulted in the high variations of the flexion angle at which ligament recruitment starts. This accounted also for the difference of the recruitment patterns between the 5 and 10 percent maximal strain criteria. Comparing the Figs. 3 and 4 , it can be noticed that where the relative length change as functions of flexion was small, the difference between flexion angles at the start or end of the $R_{5}$ and $R_{10}$ recruitment was large.

It is a rather surprising finding that, with the 5 percent maximal strain criterion, between 10 and 60 degrees flexion the anterior and posterior bundles of the cruciate ligaments were not recruited for an unloaded flexion motion. Even with the 10 percent maximal strain criterion, the anterior and posterior bundles of the PCL were not recruited between 20 and 50 degrees flexion. This means that the cruciate ligaments did not act as a single link in the guidance of the passive flexion motion, which was implied in the four-bar-linkage model of the knee (Strasser, 1917; Menschik, 1974). The recruitment of fiber bundles within the cruciate ligaments shifts gradually from posterior to anterior, which may be modelled by a shifting link in the four bar linkage model. Although not included in the present study, the intermediate fiber bundles between the most anterior and posterior bundles were probably recruited in the mid-range of flexion.

With regard to the length patterns of the collateral ligaments, there was a good agreement between the specimens in the sense that the length changes of each fiber bundle depended on its relative position in the anterior-posterior direction: the anterior fibers of these ligaments tended to retain their lengths, whereas the posterior fibers tended to relax as flexion increases. This observation is reflected in the recruitment patterns, where the anterior fiber bundles were recruited over the whole flexion range and the recruitment of the posterior fiber bundles was lost beyond a certain flexion angle. There is also a good agreement with the length patterns reported in other studies, qualitatively as well as quantitatively (Walker et al., 1988; Lewis and Lew, 1978; Warren et al., 1974; Bartel et al., 1977).

The average recruitment probability in internal and external rotation showed that, generally speaking, the cruciate ligaments were recruited in internal rotation, while in external rotation the collateral ligaments were recruited. The ACL and the posterior bundle of the PCL (pPC) were recruited with internal rotation. The anterior bundle of the PCL (aPC) behaved differently, since it was recruited with external rotation at the higher flexion angles. Ahmed et al. (1987) also reported this observation for the PCL, but then for the posterior fibers. They used buckle transducers to measure tensions in ligament fiber bundles and their attachment location on the bundle might not have been similar to the posterior bundle in this study. The restraining function of the ACL in internal rotation was confirmed by various authors (Girgis et al., 1975; Trent et al., 1976) but its significance as a primary stabilizer was questioned (Nielsen et al., 1984; Ahmed et al., 1987; Wang et al., 1973). For the lower flexion angles, the two selected bundles of the ACL were found to be recruited, but the level of recruitment is relatively low. The ACL bundles in between the anterior and posterior bundles may have compensated for this. The posterior bundle of the PCL (pPC), which was expected to cooperate with the ACL as a restraint to internal rotation, did probably transfer its function to the intermediate bundles of the ligament between 20 and 50 degrees flexion, but this remains unclear in view of the reciprocal behavior of the anterior and posterior bundles for axial rotation at 90 degrees flexion.

The MCL was thought to be the supporting restraint to internal rotation as was discussed by Ahmed et al. (1987), who measured tensions in the MCL for internal and external rotations. For external rotation the tensions were higher than for internal rotation, a finding which was supported by this study. Not supported was the finding of Ahmed et al. (1987), that the tensions for neutral tibial rotation were lower than for internal or external rotation. In this study a gradual decrease of MCL recruitment was found from external to internal rotation. This discrepancy can be explained by the bony edge of the tibia which was not taken into account in this study. Direct strain or tension measurements would be more reliable in this respect. There were also contradictory results in the literature with respect to MCL function: external restraining function (Warren et al., 1974; Jasty et al., 1982) as well as internal restraining function (Seering et al., 1980; Markolf et al., 1976) were reported. The results of this study supported only the external restraining function of the deep and superficial fibers of the MCL.

The results of the ligament recruitment with anterior-posterior forces were influenced by the coupled axial rotations which occurred, resulting in similar recruitment patterns for the cruciate ligaments and the LCL. With an anterior force at the lower flexion angles, the ACL and the MCL were recruited, while for the higher flexion angles only the anterior bundle of the ACL ( $\mathrm{aAC}$ ) may have acted as a restraint to anterior translation. With a posterior force at 20 degrees flexion, the anterior and posterior bundles of the PCL remained slack and only the lateral collateral ligament was recruited. Again the intermediate bundles of the PCL, which were not included in this study, might have contributed to the posterior restraint. The coupled external rotation was not sufficient to recruit the medial collateral ligament as well. For 90 degrees flexion the major restraint to a posterior force was the anterior bundle of the PCL (aPC). The role of the cruciate ligaments as anteriorposterior restraints and its dependence on the flexion angle was generally accepted and supported by substantial experimental data (Butler et al., 1980; Piziali et al., 1980; Fukubayashi et al., 1982; Markolf et al., 1976). For design and evaluation of clinical diagnostic tests, the results indicated that the ACL should be tested at 20 degrees flexion, since its posterior bundle will progressively loose function with increasing flexion. The recruitment of the MCL at 20 degrees flexion might be a complicating factor in the anterior laxity test at this joint position. For diagnosing partial tears, an additional test at 90 degrees flexion will reveal the status of the anterior bundle of the ACL (aAC). The PCL should be tested at 90 degrees flexion, where both the posterior (pPC) and the anterior ( $\mathrm{aPC}$ ) bundle were found to be recruited, the aPC being less variable between the different specimens than the pPC.

Generally, in all studies on ligament length patterns or lig- 
ament strains, a quantitative interpretation of the experimental results in terms of restraints to motions is difficult, not only because of the unknown initial strain or zero-load lengths of the ligaments. The restraining capacity of the ligaments do not only depend on the ligament tensions. The effectiveness of the ligament forces in restraining a particular motion depends also on its three dimensional orientation. The anterior bundle of the PCL (aPC), for example, can be expected to sustain the highest tension in full flexion, but will act merely as to compress the joint surfaces, since its orientation will be nearly parallel with the tibial axis. Secondly, the restraint to rotations, such as internal or external rotation of the tibia with respect to the femur, also depends on the relative position of the restraining ligaments of which the tensions contribute to the restraining moment through the moment arm. The restraining function of the cruciate ligaments for internal rotation is probably limited by the small moment arm between both ligaments or between a ligament and the rotation axis for axial rotations (de Lange et al., 1982). Another restraining mechanism should then assist. In external rotation the collateral ligaments are the restraining structures, in which case the moment arm is relatively large.

As shown in the present study, the choice of a limited number of bundles for a ligament gives rise to complications in the interpretation of the ligament length changes as reflections of the whole ligament mechanics. By using the concept of the minimal recruitment length, it was revealed that the most anterior and posterior bundles of the cruciate ligaments may not have been representative for the function of the ligament as a whole. This means that intermediate bundles should be taken into account as well. This as a complicating factor in those studies where the ligament strains or forces are measured by transducers attached to the superficial ligament bundles (e.g., Ahmed et al., 1987; Arms et al., 1984). Hence, the recently introduced internal force transducer for ligaments and tendons might be a good alternative for these methods (Glos et al., 1990), although the identification and the precise placement of the transducer inside a ligament is a problem that has to be solved.

Ligament strains and tensions are both the cause and the effect of joint motions in some kind of feedback mechanism. If a load is applied to the joint, the joint will move, whereby the ligaments are strained. By straining the ligaments, increasing tensions are produced, which affect the motions and thus the ligament strains and tensions. Ligament function studies, including this study, which address either the causes or the effects, remain limited as means to give insight in these complex relations. Also the interaction with other joint structures as the menisci and the articular surfaces play an important role (Blankevoort et al., 1989). However, this study did show the versatility of the minimal recruitment length and the recruitment probability as parameters in studies on ligament lengths and strains. The two recruitment parameters were based on an objective estimate for the "real" maximal strain. It may be a concise method for future ligament strain analyses where no additional data is generated with respect to the "real" zero strain lengths of the ligaments.

\section{Acknowledgment}

This research program was sponsored in part by grant $90-$ 90 from the Netherlands Organization for Research (NWO/ MEDIGON).

\section{References}

Ahmed, A. M., Hyder, A., Burke, D. L., and Chan, K. H., 1987, "In-vitro Ligament Tension Pattern in the Flexed Knee in Passive Loading," J. Orthop. Res., Vol. 5, pp. 217-230.

Arms, S., Boyle, J., Johnson, R., and Pope, M., 1983, "Strain Measurements in the Medial Collateral Ligament of the Human Knee: An Autopsy Study,"' J. Biomech., Vol. 16, pp. 491-496.
Arms, S. W., and Butler, D. L., 1989, "Cruciate Ligament Fiber Bundle Recruitment," Trans. 35th Ann. ORS, p. 190.

Bartel, D. L., Marshall, J. L., Schieck, R. A., and Wang, J. B., 1977 "Surgical Repositioning of the Medial Collateral Ligament," J.B.J.S., Vol. 59A, pp. 107-116.

Beynnon, B. D., Pope, M. H., Fleming, B. D., Howe, J. G., Johnson, R. J., Erickson, A. R., Wertheimer, C. M., and Nichols, C., 1989, "An In-vivo Study of the ACL Strain Biomechanics in the Normal Knee," Trans. 35th Ann. ORS, p. 324

Blankevoort, L., Huiskes, R., and Lange, A. de, 1988, "The Envelope of Passive Knee Joint Motion," J. Biomech., Vol. 21, pp. 705-720.

Blankevoort, L, and Huiskes, R., 1989, "An Alternative Rotation Restraint in the Knee Joint," Trains. 35th Amn. ORS, p. 26.

Butler, D. L., Noyes, F. R., Grood, E. S., 1980, "Ligamentous Restraints to Anterior-Posterior Drawer in the Human Knee," J.B.J.S., Vol. 62-A, pp. 259-270.

Claes, L. E., and Schmid, R. K., 1985, "Experimental Determination of the Mechanical Properties of Knee Ligaments," Perren, S. M., and Schneider, E. (Eds.), Biomechanics: Current Interdisciplinary Research, Martinus Nijhoff Publ., Dordrecht/Boston/Lancaster, pp. 403-408.

Crisp, J. D. C., 1972, "Properties of Tendon and Skin," Biomechanic, Its Foundations and Objectives, Y. C. Fung et al., eds., Prentice Hall, Englewoods Cliffs, N.J., pp. 141-177.

Dijk, R. van, 1983, "The Behaviour of the Cruciate Ligaments in the Human Knee," Dissertation, University of Nijmegen, Nijmegen, The Netherlands.

Dijk, R. van, Huiskes, R., and Selvik, G., 1979, "Roentgenstereophotogrammetric Methods for the Evaluation of the Three Dimensional Kinematic Behaviour and Cruciate Ligament Length Patterns of the Human Knee Joint,' J. Biomech., Vol. 12, pp. 727-731.

Fleming, B. C., Beynnon, B. D., Erickson, A. R., Pope, M. H., Wertheimer, C. M., Nichols, C., Johnson, R. J., and Howe, J. G., 1989, "An In-vivo Comparison of Anterior Joint Laxity and Strain in the Anteromedial Band of the ACL," Trans. 35th Ann. ORS, p. 326.

France, E. P., Daniels, A. U., Goble, E. M., and Dunn, H. K., 1983, "Simultaneous Quantitation of Knee Ligament Forces," J. Biomech., Vol. 16, pp. 553-564.

Fukubayashi, T., Torzilli, P. A., Sherman, M. F., and Warren, R. F., 1982, "An In-Vitro Biomechanical Evaluation of Anterior-Posterior Motion of the Knee," J.B.J.S., Vol. 64-A, pp. 179-185.

Girgis, F. G., Marshall, J. L., and Al Monajem, A. R. S., 1975, "The Cruciate Ligaments of the Knee Joint," Clin. Orthop. Rel. Res., Vol. 106, pp. 216-231.

Glos, D. L., Holden, J. P., Butler, D. L., and Grood, E. S., 1990, "Pressure Versus Deflected Beam Force Measurement in the Human Patellar Tendon," Trans. 36th Ann. ORS, p. 490.

Gollehon, D. L., Torzilli, P. A., and Warren, R. F., 1987, "The Role of the Posterolateral and Cruciate Ligaments in the Stability of the Human Knee," J.B.J.S., Vol. 69-A, pp. 233-242.

Grood, E. S., Hefzy, M. S., Butler, D. L., Suntay, W. J., Siegel, M. G., and Noyes, F. R., 1983, "On the Placement and the Initial Tension of Anterior Cruciate Ligament Substitutes," Trans. 29th Ann. ORS, p. 93.

Hefzy, M. S., and Grood, E. S., 1986, "Sensitivity of Insertion Locations on Length Patterns of Anterior Cruciate Ligaments Fibers," ASME Journal of Biomechanical ENGineERING, Vol. 108, pp. 73-82.

Hefzy, M. S., Grood, E. S., and Lindenfeld, T. L., 1986, "The Posterior Cruciate Ligament: A New Look at Length Patterns," Trans. 32th Ann. ORS, p. 128.

Henning, C. E., Lynch, M. A., Glick, K. R., 1985, "An In vivo Strain Gage Study of Elongation of the Anterior Cruciate Ligament," Am. J. Sports Med., Voi. 13 , pp. 22-26

Jasty, M., Lew, W. D., and Lewis, J. L., 1982, "In vitro Ligament Forces in the Normal Knee Using Buckle Transducers," Trans. 28th Ann. ORS, p. 241.

Kennedy, J. C., Hawkins, R. J., Willis, R. B., and Danylchuk, K. D., 1976, "Tension Studies of Human Knee Ligaments," J.B.J.S., Vol. 58-A, pp. 305 355 .

Lange, A. de, Dijk, R. van, Huiskes, R., Selvik, G., and Rens, Th. J. G., 1982, "The Application of Roentgenstereogrammetry for Evaluation of KneeJoint Kinematics In vitro," Huiskes, R., Campen, D. H. van, Wijn, J. R. de (eds.), Biomechanics: Principles and Applications, Martinus Nijhoff Publ., The Hague/Boston/London, pp. 177-184.

Lewis, J. L., and Lew, W. D., 1978, "A Method for Locating an Optimal "Fixed" Axis of Rotation for the Human Knee Joint," ASME Journal of Biomechanical Engineering, Vol. 100, pp. 187-193.

Lewis, J. L., Lew, W. D., and Schmidt, J., 1982, "A Note on the Application and Evaluation of the Buckle Transducer for Knee Ligament Force Measurement," ASME Journal of BIOMEChanICAL ENGINEERING, Vol. 104, pp. 125 128.

Markolf, K. L., Mensch, J. S., and Amstutz, H. C., 1976, "Stiffness and Laxity of the Knee-The Contributions of the Supporting Structures," J.B.J.S., Vol. 58-A, pp. 583-594.

Meglan, D., Zuelzer, W., Buck, W., and Berme, N., 1985, "Measurement of the Variation of Strain Within the Anterior Cruciate Ligament," 1985 Advances in Bioengineering, ASME, New York.

Menschik, A., 1974, "Mechanik des Kniegelenkes, 1, Teil," Z. Orthop., Vol. 112, pp. 481-495.

Nielsen, S., Ovesen, J., and Rasmussen, O., 1984, "The Anterior Cruciate 
Ligament of the Knee: An Experimental Study of Its Importance in Rotary Instability," Acta Orthop. Trauma Surg., Vol. 103, pp. 170-174.

Noyes, F. R., and Grood, E. S., 1976, "The Strength of the Anterior Cruciate Ligament in Humans and Rhesus Monkeys," J.B.J.S., Vol. 58-A, pp. 10741082.

Piziali, R. L., Seering, W. P., Nagel, D. A., and Schurman, D. J., 1980, "The Function of the Primary Ligaments of the Knee in Anterior-Posterior and Medial-Lateral Motions," J. Biomech., Vol. 13, pp. 777-784.

Seering, W. P., Piziali, R. L., Nagel, D. A:, and Schurman, D. J., 1980, "The Function of the Primary Ligaments of the Knee in Varus-Valgus and Axial Rotation," J. Biomechanics, Vol. 13, pp. 785-794.

Selvik, G., 1974, "Roentgenstereophotogrammetric Method for the Study of the Kinematics of the Skeletal System," Dissertation, University of Lund, Sweden.

Selvik, G., 1989, "Roentgen Stereophotogrammetry-A Method for the Study of the Kinematics of the Skeletal System," Acta Orthop. Scand. Suppl. 232, Vol. 60 .

Sidles, J. A., Larson, R. V., Garbini, J. L., Downey, D. J., and Matsen, F.
A. III, 1988, "Ligament Length Relationships in the Moving Knee," J. Orthop. Res., Vol. 6, pp. 593-610.

Strasser, H., 1917, "Lehrbuch der Muskel- und Gelenkmechanik," Julius Springer, Berlin.

Trent, P. S., Walker, P. S., and Wolf, B., 1976, "Ligament Length Patterns, Strength, and Rotational Axes of the Knee Joint," Clin. Orthop. Rel. Res. Vol. 117, pp. 263-270.

Viidik, A., 1980, "The Mechanical Properties of Parallel Fibered Collagenous Tissue, in: Biology of Collagen," A. Viidik and J. Vuust (eds.), Academic Press, London, pp. 237-255.

Walker, P. S., Rovick, J. S., and Robertson, D. D. 1988 "The Effects of Knee Brace Hinge Design and Placement on Joint Mechanics," $J$. Biomech., Vol. 21, pp. 965-974.

Wang, C. J., Walker, P. S., and Wolf, B., 1973, "The Effects of Flexion and Rotation on the Length Patterns of the Ligaments of the Knee," J. Biomech.

Vol. 6, pp. 587-596.

Warren, L. F., Marshall, J. L., and Girgis, F., 1974, "The Prime Static Stabilizer of the Medial Side of the Knee," J.B.J.S., Vol. 56-A, pp.665-674. 